LOQUENS 5(2)

July 2018, e053

eISSN 2386-2637

https://doi.org/10.3989/loquens.2018.053

\title{
Impact of sound stimulation during different sleep stages in patients with tinnitus
}

\author{
Marisa Pedemonte ${ }^{1,2}$, Marcela Díaz ${ }^{1,2}$, Eduardo Medina-Ferret ${ }^{3}$, Martín Testa $^{2}$ \\ ${ }^{1}$ Facultad de Medicina. Universidad CLAEH. Uruguay \\ ${ }^{2}$ Centro de Medicina del Sueño, Punta del Este, Uruguay \\ ${ }^{3}$ Escuela Universitaria de Tecnología Médica. Universidad de la República, Uruguay \\ marceladiaz.1985@gmail.com ORCID: https://orcid.org/0000-0002-5130-0287 \\ emedinaferret@gmail.com ORCID: https://orcid.org/0000-0002-4919-2862 \\ testaam@gmail.com ORCID: https://orcid.org/0000-0002-9970-0765
}

Submitted: 05/03/2018. Accepted 27/04/2018. Publicado online: 09/01/2019

Citation / Cómo citar este artículo: Marisa Pedemonte, Marcela Díaz, Eduardo Medina-Ferret and Martín Testa. (2018). Impact of sound stimulation during different sleep stages in patients with tinnitus. Loquens, 5(2), e053. https:// doi.org/10.3989/loquens.2018.053

\begin{abstract}
It is known that auditory information is continuously processed both during wakefulness and sleep. Consistently, it has been shown that sound stimulation mimicking tinnitus during sleep decreases the intensity of tinnitus and improves the patients' quality of life. The mechanisms underlying this effect are not known. To begin to address this question, eleven patients suffering from tinnitus were stimulated with sound mimicking tinnitus at different sleep stages; 4 were stimulated in N2, 4 in stage N3 (slow waves sleep) and 3 in REM sleep (stage with Rapid Eyes Movements). Patients' sleep stage was monitored through polysomnography, for sound stimulation application. Tinnitus level reported by subjects were compared the days before and after stimulation and statistically analyzed (paired Student $t$ test). All patients stimulated at stage N2 reported significantly lower tinnitus intensity the day after stimulation, while none stimulated during stage N3 and only one out of three stimulated during REM sleep showed changes. These results are consistent with studies showing that sound stimulation during N2 (sleep stage with spindles) changes power spectrum and coherence of electroencephalographic signals, and suggest that the N2 sleep stage is a critical period for reducing tinnitus intensity using this therapeutic strategy, during which auditory processing networks are more malleable by sound stimulation.
\end{abstract}

Keywords: central auditory processing; sleep spindles; sleep stages N2, N3, REM.

RESUMEN: Impacto de la estimulación sonora durante diferentes etapas del sueño en pacientes con acúfeno.- Es sabido que la información auditiva se procesa continuamente durante la vigilia y el sueño. Se ha demostrado que la estimulación con sonido que imita el tinnitus, aplicada durante el sueño, disminuye la intensidad del tinnitus y mejora la calidad de vida de los pacientes. Los mecanismos que subyacen a esta mejoría no se conocen, aunque en la etapa de sueño con husos (N2) fueron demostrados los principales cambios en los espectros de potencia y la coherencia en las ondas electroencefalográficas durante la estimulación sonora. Once pacientes que padecen tinnitus fueron estimulados por sonido (imitando el tinnitus) en diferentes etapas del sueño; 4 fueron estimulados en N2, 4 en la etapa N3 (sueño de ondas lentas) y 3 durante el sueño REM (estadio con movimientos oculares rápidos). Los pacientes fueron registrados con una polisomnografía, para el diagnóstico de etapas del sueño y la aplicación de la estimulación del sonido. Los valores de intensidad del tinnitus se compararon los días anterior y posterior a la estimulación y se analizaron estadísticamente (prueba $t$ de Student pareada). Todos los pacientes estimulados en la etapa N2 mostraron una disminución estadísticamente significativa en la intensidad del tinnitus el día después de la estimulación, mientras que ninguno de los pacientes estimulados en la etapa N3 mostró cambios en la intensidad, y solo uno de los tres estimulados durante el sueño REM tuvo cambios. Los resultados sugieren que la etapa de sueño N2 sería el período en que el sonido estimulante interactuaría con las redes de procesamiento auditivo, reduciendo la intensidad del tinnitus.

Palabras clave: procesamiento auditivo central; husos de sueño; etapas N2, N3 y REM.

Copyright: (C) 2018 CSIC. Este es un artículo de acceso abierto distribuido bajo los términos de la licencia de uso y distribución Creative Commons Reconocimiento 4.0 Internacional (CC BY 4.0). 


\section{INTRODUCTION}

From Aristotle to our days, it has been generally accepted that sensory integration is not abolished by sleep (Aristotle, trans. in 1955; Burton, Harsh, \& Badia, 1988; Halász, 1988; Maury, 1878). Among sensory modalities, audition is particularly important as a telereceptor that remains open during sleep (Velluti, 1997, 2018). The auditory input throughout the day is processed and consolidated as a memory during sleep. Furthermore, the Central Nervous System (CNS) continues processing information that enters from the environment, since the auditory system remains as a sentinel during sleep, capable of receiving information, analyzing it, and generating a response. The maternal waking up by baby crying is an example of stimuli considered significant among information stored in memory detected and recognized while asleep (Formby, 1967). Also hearing our own name or a potentially dangerous sound (Halász, Terzano, Parrino, \& Bodizs, 2004) can selectively induce waking. Furthermore, auditory contents are reported in $65 \%$ of dreams (Hobson, 1990; McCarley \& Hoffman, 1981) and sensory information can be incorporated into them (Bastuji \& García-Larrea, 2005).

However, sensory processing during sleep has been the subject of considerable controversy. Some studies have proposed a functional disconnect between the cerebral cortex and external auditory input (Jones, 1991; Steriade, 1997) supported by electrophysiological evidence indicating changes in sensory processing at the thalamic level (Pompeiano, 1970; Steriade, Gloor, Llinas, Lopes da Silva, \& Mesulam, 1990).

Furthermore, changes in neuronal activity linked to sleep-wake cycle have been reported along the entire auditory pathway in animals and humans (Issa \& Wang, 2008; Pedemonte, Peña, Morales-Cobas, \& Velluti, 1994; Pedemonte, Peña, \& Velluti, 1996b; Pedemonte, PérezPerera, Peña, \& Velluti, 2001; Peña, Pedemonte, Ribeiro, \& Velluti, 1992; Peña, Pérez-Perera, Bouvier, \& Velluti, 1999). Changes in the receptive field of cortical auditory neurons (Edeline, Dutrieux, Manunta, \& Hennevin, 2001) and in evoked responses (Erwin \& Buchwald, 1986; Osterhammel, Shallop, \& Terkildsen, 1985) were also reported.

Additionally, hearing loss changes the sleep-wake cycle and the sleep architecture (Cutrera et al., 2000; Pedemonte, Peña, Torterolo, \& Velluti, 1996a). Also, patients with intracochlear implants display differences in sleep architecture and electroencephalographic signals when the implant is switched on or off (Velluti, Pedemonte, Suárez, Bentancor, \& Rodriguez-Servetti, 2010).

Despite there is a consensus that sleep is involved in learning and memory processing (from Müller \& Pilzecker, 1900; Jenkins and Dallenbach, 1924), the role of each stage in the formation of different types of memory remains an open question. While REM sleep has been involved in the consolidation of working memory, slow wave sleep has been linked to declarative memory
(Cipolli et al., 1988; Cipolli, Fagioli, Mazzeti, \& Tuozzi, 2005). Slow oscillations of EEG have been involved in the consolidation of long-term memory, in homeostatic regulation of synaptic connections, and in the consolidation of memory and post-sleep facilitation to codify new memories (Diekelmann \& Born, 2010; Marshall, Helgadottir, Mölle, \& Born, 2006; Tononi \& Cirelli, 2006). Moreover, the integrity and interaction of the different sleep stages appears to be essential for memory consolidation (Cipolli, 2005; De Gennaro, Ferrara, \& Bertini, 2000; Mölle, Bergmann, Marshall, \& Born, 2011).

Rhythmic acoustic stimulation induces $\mathrm{K}$-complexes, which are considered a "forerunner" of slow oscillations in slow waves sleep stage (De Gennaro, Ferrara, \& Bertini, 2000; Riedner, Hulse, Murphy, Ferrarelli, \& Tononi, 2011). Likewise, slow waves may be modulated by low frequency auditory stimulation (Ngo, Claussen, Born, \& Mölle, 2013). Studies with functional magnetic resonance showed that auditory cortical activity is maintained during sleep but varies with stimulus significance (Maquet et al., 2005; Portas et al., 2000).

Taking into account the aforementioned evidence and the premise of subjective tinnitus as an anomalous perception resulting from dysfunctionality of neuronal plasticity (Andersson et al., 2000; Jastreboff, 1990; Melcher, Sigalovsky, Guinan, \& Levine, 2000), a therapeutic strategy using acoustic stimulation during sleep was developed, resulting in decrease in the reported intensity of tinnitus and improvement in the patients' quality of life (Drexler et al., 2016; Pedemonte, 2018; Pedemonte et al., 2010). Despite the changes produced by this stimulation protocol, the electrophysiological mechanisms underlying these changes are not yet known.

Our aim was to explore whether neural network reorganization induced by external stimulation is enhanced in a particular sleep stage and be used more effectively to reduce the perception of tinnitus.

\section{METHODS}

Eleven patients suffering idiopathic tinnitus ( 6 females, 5 males; between 32 and 69 years old; tinnitus evolution between 6 months and 20 years) participated in this study. The inclusion criteria were: (1) subjects with subjective idiopathic tinnitus (unilateral or bilateral), (2) with a score in the Tinnitus Handicap Inventory above 17, and (3) experiencing tinnitus for more than 6 months. The exclusion criteria were: (1) secondary tinnitus, (2) subjects wearing hearing aids or having hearing loss with indication of using them, (3) subjects undergoing other treatments for tinnitus, (4) use of hypnotic or other psychoactive drugs, (5) depression (Hamilton scale test above 13) and (6) sleep disorders other than those caused by tinnitus itself, for example patients with apnea, restless legs syndrome, narcolepsy, and insomnia with other etiology than tinnitus.

Four out of 11 subjects had monaural tinnitus ( 3 at the left and 1 at the right). The spectral characteristics of the perceived sound were a combination of bandpass noise 
and pure tones in 4 patients; a combination of pure tones was referred by 4 and a pure tone alone by 3 .

Combinations of pure tones, harmonic tone stacks, white noise and/or bandpass noise were designed for matching each patient's perception by a highly customized sound. This sound was loaded on an iPod Touch and delivered through personalized headphones created for each patient. The stimulus intensity was adjusted to match the intensity of the tinnitus measured right before falling asleep. The device used was the same as in the clinical trials (Drexler et al., 2016).

The stage of sleep in which each patient was stimulated was selected at random; 4 patients were stimulated in the Stage N2 (sleep stage characterized by spindles; Figure 1.A), 4 in Stage N3 (sleep with slow waves; Figure 2.A) and 3 in REM sleep (stage with Rapid Eye
Movements; Figure 3.A). Patients were recorded with a complete Polysomnography, for sleep stages diagnosis (from 10 p.m. to 6 a.m.). The Polysomnography (PSG, traces in A) was carried out under a usual clinical protocol with a computerized polysomnograph, recording 10 electroencephalographic channels (frontals: F3, F4; centrals: C3, C4; parietals: P3, P4; temporal: T3, T4, T5, T6, following the internationally standard denomination), electrocardiogram (EKG), respiratory movements (Resp), eye movements (EOG) electromyograms (EMG1 and EMG2), and oximetry (not shown). A researcher monitored the patient and performed online diagnosis of sleep stages turning "on" and "off" the sound in the corresponding sleep stage according to the protocol. The total time of stimulation was the same in all patients (90 minutes) always in the selected stage for each one.

Figure 1: Patients stimulated with sound mimicking tinnitus in stage N2 of sleep. A, 3 seconds of raw recorded traces, characteristic of stage N2, 10 electroencephalographic channels (EEG frontal: F3, F4; centrals: C3, C4; parietal: P3, P4; temporal: T3, T4, T5, T6; electrocardiogram (EKG); respiratory movements (Resp); eye movements (EOG); electromyogram (EMG1, masseter muscle, and EMG2, right leg). EEG shows characteristic spindles. B, three patients were stimulated during N2 in both ears (BL, MM and ADe) and one $(\mathrm{CH})$ was stimulated on the left ear only. Each bar represents the average and standard deviation of 10 tinnitus intensities before (Pre) and after (Post) stimulation. Inset, (in $\mathrm{CH}$ ) represents intensity averages of 5 values in the morning, before and after sound stimulation. Student $t$ test, $* \mathrm{p} \leq 0.05, * * \mathrm{p} \leq 0.01$. See explanation in the text.

A

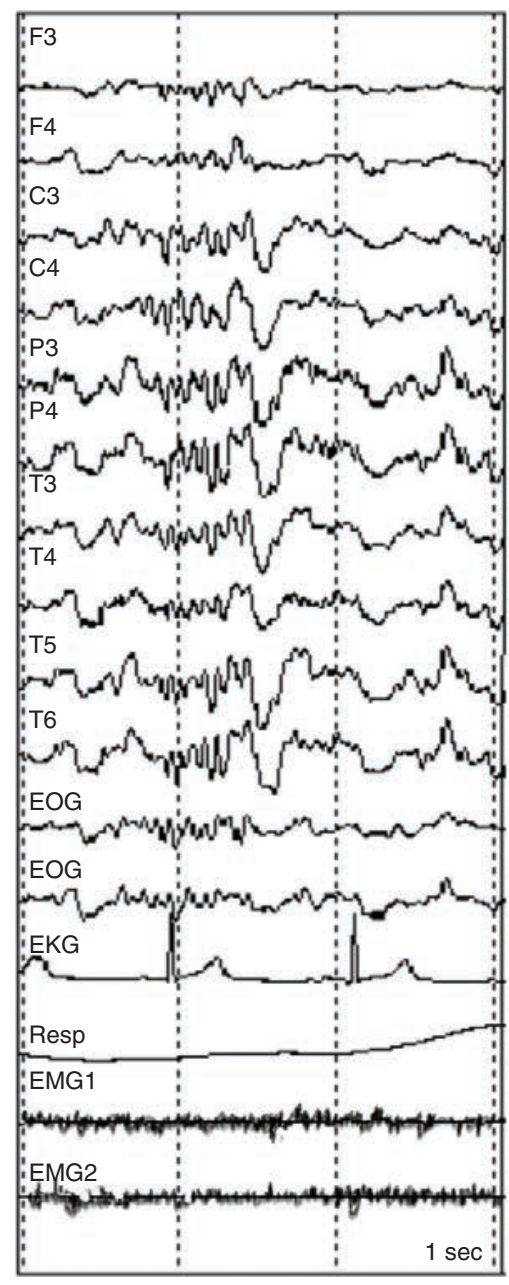

B

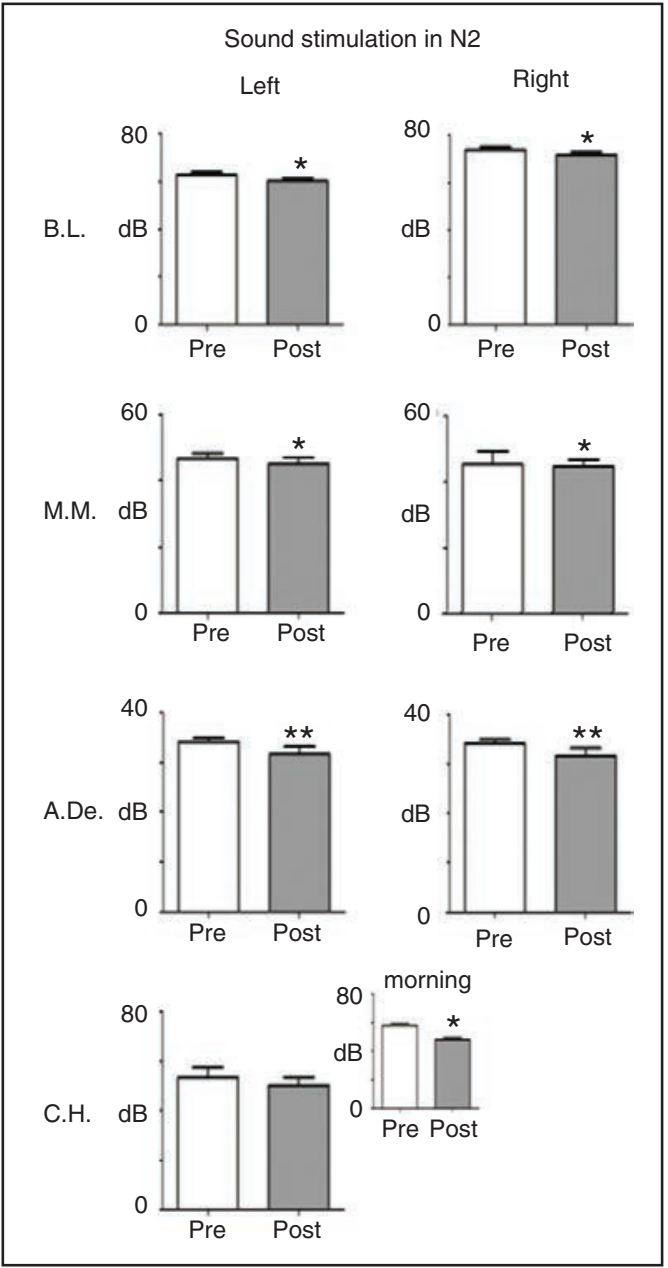


Figure 2: Patients stimulated with sound mimicking tinnitus in Stage N3 of sleep. Same display as in Figure 1. A, Stage N3 characterized by slow waves. B, three subjects were stimulated in both ears (JC, Adi, and LF) and one (WM) was stimulated in the right ear. No significant changes were found.

A

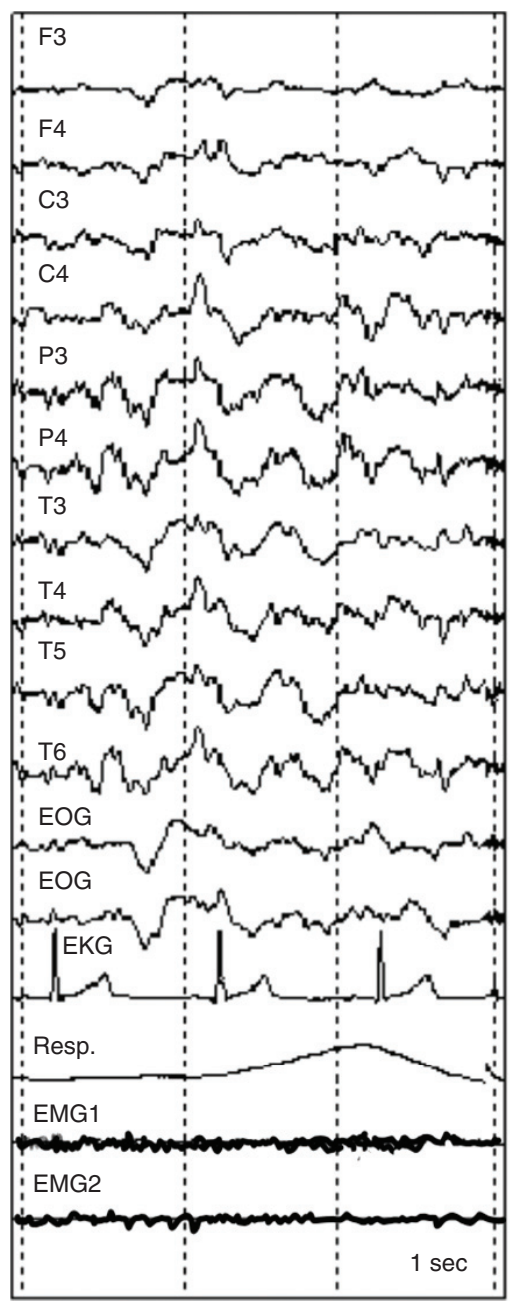

B

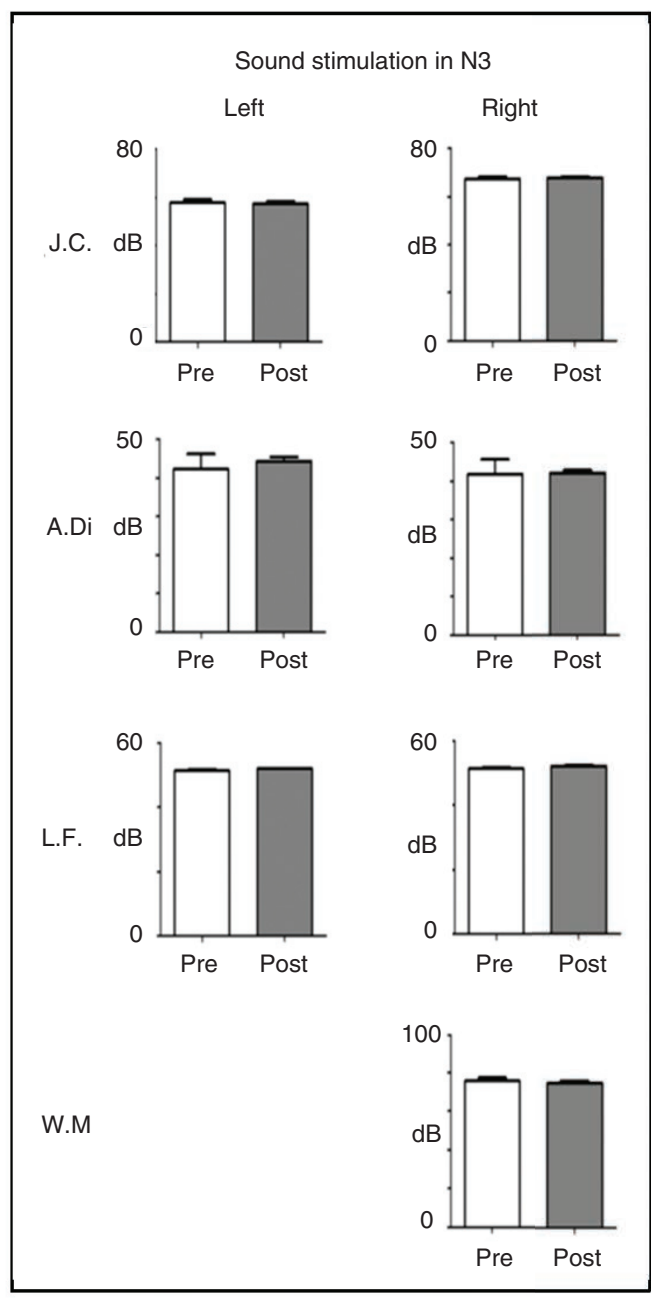

Recordings were conducted after 2 to 4 nights of training with the stimulation device. Both the sleep architecture (temporal sequence of sleep stages) and the percent time of each stage within the total sleep time and the number of awakenings (sleep efficiency) were within normal ranges in the night of sound stimulation.

The intensity of tinnitus was measured 10 times during the day prior to stimulation compared with the intensity of tinnitus measured 10 times the day after stimulation, and analyzed statistically (paired Student $t$ test). The measurements had at least one hour of separation between them. The criterion for measuring tinnitus intensity was the lowest level of sound stimulation reported as indistinguishable from the tinnitus perception. This measurement was conducted using the stimulation application, which can be adjusted within safe ranges, by the patients themselves (the device described in Drexler et al, 2016, was used).
This research has been approved by the Ethical Committee of the School of Medicine of CLAEH University, according to the International Ethic Guidelines for Human Research. Patients were informed and signed a letter of consent.

\section{RESULTS}

All patients stimulated at stage N2 showed statistically significant decrease in tinnitus intensity the day after stimulation (Figure 1, Table 1).

The three patients stimulated in both ears presented significant decrease in the intensity of tinnitus the day after the stimulation. The patient with unilateral tinnitus reported a decrease in tinnitus after stimulation that reached statistical significance only when five intensity measurements performed in the morning before and after the stimulation were compared. 
Figure 3: Patients stimulated with sound mimicking tinnitus in REM sleep stage. Same description as in Figure 1. A, Stage characterized by rapid eye movements, muscle atonia and twitches, and electroencephalographic desynchronization. B, two subjects were stimulated in the right ear (FA and FH) and one in both ears (MR). One out of three showed significant changes after stimulation. Student $t$ test, ${ }^{* * *} \mathrm{p} \leq 0.001$.

A

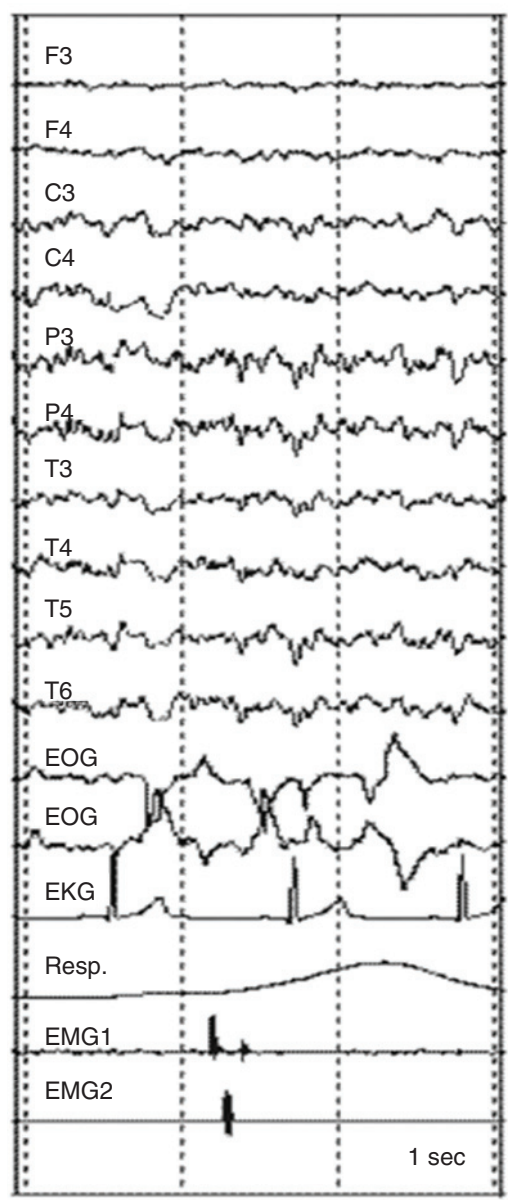

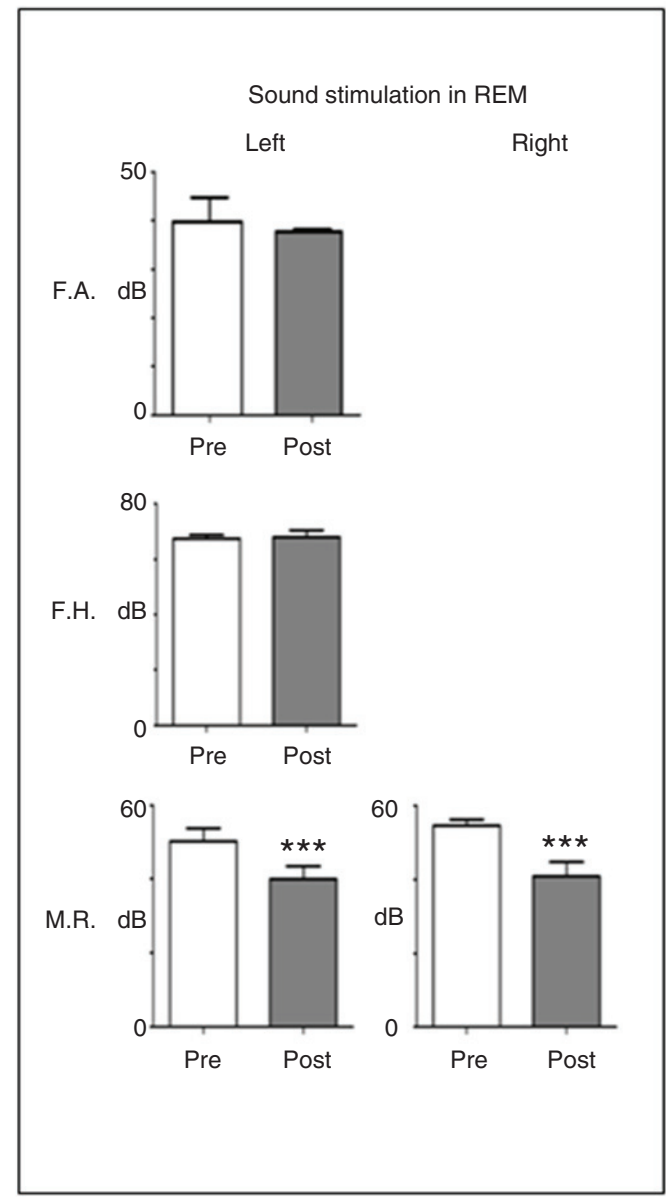

No patient stimulated in stage $\mathrm{N} 3$ reported changes in the intensity of tinnitus (Figure 2, Table 1).

Only one patient out of three stimulated during REM sleep reported changes (Figure 3, Table 1).

\section{DISCUSSION AND CONCLUSIONS}

Although treatments for tinnitus have been varied, in recent decades sound stimulation has become a method for improving it. Since understanding that tinnitus arises from a disturbance in central auditory processing (Jastreboff, 1995), a treatment based on manipulating neural plasticity through sound stimulation appears reasonable. The protocols developed towards this strategy have also varied, from Tinnitus Retraining Therapy (TRT), a behavioral treatment that tries to psychologically disconnect the patient from the dependence on tinnitus (Kroener-Herwig, 2000), music therapy (Kusatz, Ostermann, \& Aldridge, 2005), to sounds with different degrees of complexity (Heijneman, De Kleine, \& Van
Dijk, 2012; Hoare, Searchfield, El Refaie, \& Henry, 2014; Noreña \& Eggermont, 2005; Pantev, Okamoto, \& Teismann, 2012; Reavis et al., 2012; Schaette, König, Hornig, Gross, \& Kempter, 2010; Vermeire, Heyndrickx, De Ridder, \& Van De Heyning, 2007; Wazen et al., 2011; Wilde, Steed, \& Hanley, 2008). In the last decade a protocol of treatment with sound stimulation during the night has been developed (Drexler et al., 2016; Pedemonte et al., 2010). It is not clear yet what is the most effective form of stimulation or when to apply it (Theodoroff et al., 2017). The proposal of relearning an auditory perception mediated by a nocturnal consolidation mechanism that depends on the sleep phase will also shed light on whether the auditory system interacts differently with sensory inputs across stages.

Our results suggest that $\mathrm{N} 2$ is the sleep stage when the interaction between auditory processing and sleep generating networks leads to the strongest reduction in tinnitus intensity by external sound stimulation. These results are consistent with the previous results that showed more 
Table 1: Averages of patients' tinnitus intensities (with standard deviations) before and after sound stimulation during sleep stages N2, N3, and REM.

\begin{tabular}{|c|c|c|c|c|}
\hline \multicolumn{5}{|c|}{ N2 stimulation } \\
\hline & \multicolumn{4}{|c|}{ dB } \\
\hline \multirow[t]{2}{*}{ Patient } & \multicolumn{2}{|c|}{ left ear } & \multicolumn{2}{|c|}{ right ear } \\
\hline & before & after & before & after \\
\hline B.L & $63.6 \pm 1.5$ & $60.1 \pm 1.5 *$ & $73.9 \pm 1.5$ & $72.0 \pm 1.2 *$ \\
\hline M.M & $46.7 \pm 1.8$ & $45.1 \pm 2.1 *$ & $45.5 \pm 4.3$ & $44.6 \pm 2.2 *$ \\
\hline A.De & $34.1 \pm 0.8$ & $31.6 \pm 1.6 * *$ & $34.1 \pm 0.8$ & $31.6 \pm 1.6 * *$ \\
\hline C.H & $57.8 \pm 1$ & $47.8 \pm 1.7 *$ & & \\
\hline \multicolumn{5}{|c|}{ N3 stimulation } \\
\hline & \multicolumn{4}{|c|}{ dB } \\
\hline \multirow[t]{2}{*}{ Patient } & \multicolumn{2}{|c|}{ left ear } & \multicolumn{2}{|c|}{ right ear } \\
\hline & before & after & before & after \\
\hline J.C & $57.8 \pm 1.4$ & $57.4 \pm 1.0$ & $67.4 \pm 0.9$ & $67.6 \pm 0.8$ \\
\hline A.Di & $42.3 \pm 3.9$ & $44.4 \pm 1.1$ & $41.9 \pm 3.7$ & $42.1 \pm 0.7$ \\
\hline L.F & $51.4 \pm 0.5$ & $52 . \pm 0 *$ & $51.4 \pm 0.5$ & $52.0 \pm 0.6$ \\
\hline W.M & & & $75.6 \pm 1.5$ & $75.1 \pm 0.9$ \\
\hline \multicolumn{5}{|c|}{ REM stimulation } \\
\hline & \multicolumn{4}{|c|}{ dB } \\
\hline \multirow[t]{2}{*}{ Patient } & \multicolumn{2}{|c|}{ left ear } & \multicolumn{2}{|c|}{ right ear } \\
\hline & before & after & before & after \\
\hline F.A & $39.8 \pm 4.9$ & $37.7 \pm 0.6$ & & \\
\hline F.H & $67.6 \pm 1.1$ & $68.2 \pm 2.3$ & & \\
\hline M.R & $50.3 \pm 3.6$ & $40.1 \pm 3.5^{* *}$ & $54.6 \pm 1.7$ & $40.9 \pm 3.8 * *$ \\
\hline
\end{tabular}

$* \mathrm{p} \leq 0.05$

$* * \mathrm{p} \leq 0.01$

changes in electroencephalographic wave's coherence in N2 sleep stage during sound stimulation (Pedemonte, Testa, Díaz, \& Suárez-Bagnasco, 2014). Morever, sleep spindles, characteristic of N2 sleep stage, are those that change their intra and interhemispheric coherence. Pedemonte et al. (2014) show that the theta frequency range is the one that most increases its power spectrum with sound stimulation with the greatest increases in the N3 stage, while our results show no change in the intensity of tinnitus in this stage of sleep. According to studies in animal models, the theta rhythm can appear phase-locked with the auditory neuronal discharges in all stages of the wake-sleep cycle (Pedemonte, Peña, \& Velluti, 1996b, 2001). This temporal correlation has also been seen in visual neurons (Gambini, Velluti, \& Pedemonte, 2002). Theta rhythm is postulated as a temporary organizer, a "time giver", to sequentially organize sensory inputs. The notion that theta rhythm changes are dependent on the animal's attention state during behavior was postulated several decades ago (Kemp \& Kaada, 1975; Vinogradova, 2001; Wallenstein, Eichenbaum, \& Hasselmo, 1998). Apparently this temporal correlation can be caused by changes in the sensory input; therefore theta rhythm would officiate more as a novelty sensor than in the processing of specific sensory information (Liberman, Velutti, \& Pedemonte, 2009; Pedemonte, Gambini, \& Velutti, 2005).

Knowing what a sensory input does in the brain when stimulated is still a great challenge. We assume it interacts with information stored in memory, which is expressed through the efferent control systems, with genetic information, which is processed with an emotional-affective load and is processed differently depending on the state of the brain the recipient, such as sleep or waking with different nuances. This research contributes data about the best stage for correcting anomalous auditory perception through sound sensory stimulation during sleep.

\section{ACKNOWLEDGMENTS}

We are grateful to Dr. Daniel Drexler for the audiological evaluation of the patients and to Dr. José Luis Peña (Albert Einstein College of Medicine) for comments on the manuscript. This work received partial financial support from the Cedars Sinai Medical Center, Los Angeles, USA.

\section{REFERENCES}

Andersson, G., Lyttkens, L., Hirvela, C., Furmark, T., Tillfors, M., \& Fredrikson, M. (2000). Regional cerebral blood flow during tinnitus: A PET case studied with lidocaine and auditory stimulation. Acta Oto-Laringologica, 120(8), 967-972. https://doi.org/10.1080/00016480050218717

Aristotle (trans. 1955). In W. D. Ross (Ed.), Parva naturalia. De divinatione per somnum. Oxford: Clarendon Press.

Bastuji, H., \& García-Larrea, L. (2005). Human auditory information processing during sleep assessed with evoked potentials. In P. L. Parmeggiani \& R. A. Velluti (Eds.), The Physiologic Nature of Sleep (pp. 509-534). London: Imperial College Press. https://doi.org/10.1142/9781860947186_0023

Burton, S. A., Harsh, J. R., \& Badia, P. (1988). Cognitive activity in sleep and responsiveness to external stimuli. Sleep, 11, 61-68.

Cipolli, C. (2005). Sleep and memory. The Physiologic Nature of Sleep (pp. 601-629). London: Imperial College Press. https://doi.org/10.1142/9781860947186_0026

Cipolli, C., Fagioli, I., Baroncini, P., Fumai, A., Marchiò, B., \& Sancini, M. (1988). The thematic continuity in mental experiences in REM and NREM sleep. International Journal of Psychophysiology, 6, 307-313. https://doi.org/ 10.1016/0167-8760(88)90018-9

Cipolli, C., Fagioli, I., Mazzetti, M., \& Tuozzi, G. (2005). Consolidation effect of the processing of declarative knowledge during human sleep: Evidence from long-term retention of interrelated contents of mental sleep experiences. Brain Research Bulletin, 65, 97-104. https://doi. org/10.1016/j.brainresbull.2004.10.014

Cutrera, R., Pedemonte, M., Vanini, G., Goldstein, N., Savorini, D., Cardinali, D. P., \& Velluti, R. A. (2000). Auditory deprivation modifies biological rhythms in the golden hamster. Archives Italiennes de Biologie, 138, 285-293.

Diekelmann, S., \& Born, J. (2010). The memory function of sleep. Natural Revues Neuroscience, 11, 114-126. https:// doi.org/10.1038/nrn2762

Drexler, D., López-Paullier, M., Rodio, S., González, M., Geisinger, D., \& Pedemonte, M. (2016). Impact of 
reduction of tinnitus intensity on patients' quality of life. International Journal of Audiology, 55(1), 11-19. https:// doi.org/10.3109/14992027.2015.1072772

Edeline, J. M., Dutrieux, G., Manunta, G., \& Hennevin, E. (2001). Diversity of receptive field changes in auditory cortex during natural sleep. European Journal of Neuroscience, 14, 18651880. https://doi.org/10.1046/j.0953-816x.2001.01821.x

Erwin, R., \& Buchwald, J. (1986). Midlatency auditory evoked responses: Differential effects of sleep in the human. Electroencephalography and Clinical Neurophysiology, 65, 383-392. https://doi.org/10.1016/0168-5597(86)90017-1

Formby, D. (1967). Maternal recognition of infant's cry. Developmental Medicine and Child Neurology, 9, 293-298. https://doi.org/10.1111/j.1469-8749.1967.tb02271.x

Gambini, J. P., Velluti, R. A., \& Pedemonte, M. (2002). Hippocampal theta rhythm synchronizes visual neurons in sleep and waking. Brain Research, 926, 137-141. https:// doi.org/10.1016/S0006-8993(01)03321-2

De Gennaro, L., Ferrara, M., \& Bertini, M. (2000). The spontaneous K-complex during stage 2 sleep: Is it the "forerunner" of delta waves? Neuroscience Letters, 291, 41-43. https:// doi.org/10.1016/S0304-3940(00)01366-5

Halász, P. (1988). Onformation processing during sleep. In W. P. Koella, F. Obál, H. Schulz, \& P. Visser (Eds.), Sleep'86 (pp: 77-78). Stuttgart: Fischer.

Halász, P., Terzano, M., Parrino, L., \& Bodizs, R. (2004). The nature of arousal in sleep. Journal of Sleep Research, 13, 1-23. https://doi.org/10.1111/j.1365-2869.2004.00388.x

Heijneman, K. M., De Kleine, E., \& Van Dijk, P. (2012). A randomized double-blind crossover study of phase-shift sound therapy for tinnitus. Otolaryngology-Head and Neck Surgery (USA), 147(2), 308-315. https://doi.org/ 10.1177/0194599812442615

Hoare, D. J., Searchfield, G. D., El Refaie, A., \& Henry J. A. (2014). Sound therapy for tinnitus management: Practicable options. Journal of the American Academy of Audiology, 25, 62-75. https://doi.org/10.3766/jaaa.25.1.5

Hobson, J. A. (1990). Sleep and dreaming. Journal of Neuroscience, $10, \quad 371-382 . \quad$ https://doi.org/10.1523/ JNEUROSCI.10-02-00371.1990

Issa, E. B., Wang, X. (2008). Sensory responses during sleep in primate primary and secondary auditory cortex. Journal of Neuroscience, 28, 14467-14480. https://doi.org/10.1523/ JNEUROSCI.3086-08.2008

Jastreboff, P. J. (1990). Phantom auditory perception (tinnitus): mechanisms of generation and perception. Neuroscience Research, 8, 221-254. https://doi.org/10.1016/0168-0102(90) 90031-9

Jastreboff, P. J. (1995). Tinnitus as a phantom perception: theories and clinical implications. In J. A. Vernon \& A. R. Møller (Eds.), Mechanisms of tinnitus (73-93). Boston, MA: Allyn \& Bacon.

Jenkins, J. K., \& Dallenbach, K. M. (1924). Obliviscence during sleep and waking. American Journal of Psychology, 35, 605-612. https://doi.org/10.2307/1414040

Jones, B. E. (1991). Paradoxical sleep and its chemical/structural substrates in the brain. Neuroscience, 40, 637-656. https:// doi.org/10.1016/0306-4522(91)90002-6

Kemp, I. R., Kaada, B. R. (1975). The relation of hippocampal theta activity to arousal, attentive behaviour and somatomotor movements in unrestrained cats. Brain Research, 95, 323-342. https://doi.org/10.1016/0006-8993(75)90110-9

Kroener-Herwig, B., Biesinger, E., Gerhards, F., Goebel, G., Verena-Greimel, K, \& Hiller, W. (2000). Retraining Therapy for chronic tinnitus. A critical analysis of its status. Scandinavian Audiology, 29, 67-78. https://doi.org/ $10.1080 / 010503900424471$

Kusatz, M., Ostermann, T., \& Aldridge, D. (2005). Auditory stimulation therapy as an intervention in subacute and chronic tinnitus: A prospective observational study. International Tinnutis Journal, 11(2), 163-169.

Liberman, T., Velluti, R. A., \& Pedemonte, M. (2009). Temporal correlation between auditory neurons and the hippocampal theta rhythm induced by novel stimulations in awake guinea pigs. Brain Research, 1298, 70-77. https://doi.org/ 10.1016/j.brainres.2009.08.061
Maquet, P. A. A., Sterpenich, V., Albouy, G., Dang-bu, T., Desseilles, M. Boly, M. et al. (2005). Brain imaging on passing to sleep. The Physiologic Nature of Sleep (pp. 123-138). London: Imperial College Press. https://doi. org/10.1142/9781860947186_0006

Marshall, L., Helgadottir, H., Mölle, M., Born, \& J. (2006). Boosting slow oscillations during sleep potentiates memory. Nature, 444, 610-613. https://doi.org/10.1038/nature05278

Maury, A. (1878). Le sommeil et les rêves $\left(4^{\text {th }}\right.$ ed.). Paris: Didier, pp. 61-162.

McCarley, R. W., \& Hoffman, E. (1981). REM sleep dreams and the activation synthesis hypothesis. American Journal of Psychiatry, 138, 904-912. https://doi.org/10.1176/ajp. 138.7.904

Melcher, J. R., Sigalovsky, I. S., Guinan, J. J. Jr., \& Levine, R. A. (2000). Lateralized tinnitus studied with functional magnetic resonance imaging: abnormal inferior colliculus activation. Journal of Neurophysiology, 83(2), 1058-1072. https://doi.org/10.1152/jn.2000.83.2.1058

Mölle, M., Bergmann, T. O., Marshall, L., \& Born, J. (2011). Fast and slow spindles during the sleep slow oscillation: Disparate coalescence and engagement in memory processing. Sleep, 34, 1411-1421. https://doi.org/10.5665/ SLEEP. 1290

Müller, G. E., \& Pilzecker, A. (1900). Experimentelle Beiträge zur lehre vom Gedächtniss. Zeitschrift für Psychologie und Physiologie der Sinnesorgane, 1, 1-300.

Ngo, H.-V. V. Claussen, J. C. Born, J. \& Mölle, M. (2013). Induction of slow oscillations by rhythmic acoustic stimulation. Journal of Sleep Research, 22, 22-31. https://doi. org/10.1111/j.1365-2869.2012.01039.x

Noreña, A. J., \& Eggermont, J. J. (2005). Enriched acoustic environment after noise trauma reduces hearing oss and prevents cortical map reorganization. Journal of Neuroscience, 25, 699-705. https://doi.org/10.1523/ JNEUROSCI.2226-04.2005

Osterhammel, P., Shallop, J., \& Terkildsen, K. (1985). The effects of sleep on the auditory brainstem response (ABR) and the middle latency response (MLR). Scandinavian Audiology, 14, 47-50. https://doi.org/10.3109/01050398509045921

Pantev, C., Okamoto, H. \& Teismann, H. (2012). Tinnitus: The dark side of the auditory cortex plasticity. Annals of the New York Academy of Science, 1252(1), 253-258. https:// doi.org/10.1111/j.1749-6632.2012.06452.x

Pedemonte, M. (2018). Chapter 7. Tinnitus treatment during sleep. In Velluti, R. A. (Ed.), The auditory system in sleep (2nd ed.) (pp. 161-184). Elsevier-Academic Press, United Kingdom. https://doi.org/10.1016/B978-0-12-810476-7.00007-5

Pedemonte, M., Drexler, D., Rodio, S., Geisinger, D., Bianco, A., Pol-Fernandes, D., \& Bernhardt V. (2010). Tinnitus treatment with sound stimulation during sleep. The International Tinnitus Journal, 16, 37-43.

Pedemonte, M., Gambini, J. P., \& Velluti, R. A. (2005). Novelty-induced correlation between visual neurons and the hippocampal theta rhythm in sleep and wakefulness. Brain Research, 1062, 9-15. https://doi.org/10.1016/j. brainres.2005.07.069

Pedemonte, M., Peña, J. L., Morales-Cobas, G., \& Velluti, R. A. (1994). Effects of sleep on the responses of single cells in the lateral superior olive. Archives Italiennes de Biologie, $132,165-178$

Pedemonte, M., Peña, J. L., Torterolo, P., Velluti, R. A. (1996a). Auditory deprivation modifies sleep in guineapig. Neuroscience Letters, 223,1-4. https://doi.org/10.1016/ S0304-3940(97)13392-4

Pedemonte, M., Peña, J. L., \& Velluti, R. A. (1996b). Firing of inferior colliculus auditory neurons is phase-locked to the hippocampus theta rhythm during paradoxical sleep and waking. Experimental Brain Research, 112, 41-46. https:// doi.org/10.1007/BF00227176

Pedemonte, M., Pérez-Perera, L., Peña, J. L., \& Velluti, R. A. (2001). Auditory processing during sleep: Correlation of cortical unitary activity with hippocampus theta Rhythm. Sleep Research Online, 4, 52-57.

Pedemonte, M., Testa, M., Díaz, M., \& Suárez-Bagnasco, D. (2014). The impact of sound on electroencephalographic 
waves during sleep in patients suffering from tinnitus. Sleep Science, 7(3), 143-151. https://doi.org/10.1016/j.slsci. 2014.09.011

Peña, J. L., Pedemonte, M., Ribeiro, M. F., \& Velluti, R. A. (1992). Single unit activity in the guinea-pig cochlear nucleus during sleep and wakefulness. Archives Italiennes de Biologie, 130, 179-189.

Peña, J. L., Pérez-Perera, L., Bouvier, M., \& Velluti, R. A. (1999). Sleep and wakefulness modulation of the neuronal firing in the auditory cortex of the guinea-pig. Brain Research, 816, 463-470. https://doi.org/10.1016/S0006-8993(98)01194-9

Pompeiano, O. (1970). Mechanisms of sensory-motor integration during sleep. Progress in Physiological Psychology, $3,1-179$.

Portas, C., Krakow, K., Allen, P., Joseph, O., Armony, J.L., \& Frith, C.D. (2000). Auditory processing across the sleepwake cycle: Simultaneous EEG and fMRI monitoring in humans. Neuron, 28, 991-999. https://doi.org/10.1016/ S0896-6273(00)00169-0

Reavis, K. M., Rothholtz, V. S., Tang, Q., Carroll, J. A., Djalilian, H., \& Zeng, F. G. (2012). Temporary suppression of tinnitus by modulated sounds. Journal of the Association for Research in Otolaryngology, 13(4), 561-571. https://doi. org/10.1007/s10162-012-0331-6

Riedner, B. A., Hulse, B. K., Murphy, M. J., Ferrarelli, F., \& Tononi, G. (2011). Temporal dynamics of cortical sources underlying spontaneous and peripherally evoked slow waves. Progress in Brain Research, 193, 201-218. https:// doi.org/10.1016/B978-0-444-53839-0.00013-2

Schaette, R., König, O., Hornig, D., Gross, M., \& Kempter, R. (2010). Acoustic stimulation treatments against tinnitus could be most effective when tinnitus pitch is within the stimulated frequency range. Hearing Research, 269, 95-101. https://doi.org/10.1016/j.heares.2010.06.022

Steriade, M. (1997). Synchronized activities of coupled oscillators in the cerebral cortex and thalamus at different levels of vigilance. Cerebral Cortex, 7, 583-604. https://doi. org/10.1093/cercor/7.6.583

Steriade, M, Gloor, P., Llinas, R. R., Lopes da Silva, F. H., \& Mesulam, M. M. (1990). Report of IFCN Committee on Basic Mechanisms. Basic mechanisms of cerebral rhythmic activities. Electroencephalography and Clinical
Neurophysiology, 76, 481-508. https://doi.org/10.1016/ 0013-4694(90)90001-Z

Theodoroff, S. M., McMillan, G. P., Zaugg, T. L., Cheslock, M., Roberts, C., \& Henry, J. A. (2017). Randomized controlled trial of a novel device for tinnitus sound therapy during sleep. American Journal of Audiology, 26, 543-554. https:// doi.org/10.1044/2017_AJA-17-0022

Tononi, G., \& Cirelli, C. (2006). Sleep function and synaptic homeostasis. Sleep Medicine Reviews, 10, 49-62. https:// doi.org/10.1016/j.smrv.2005.05.002

Velluti, R. A. (1997). Interactions between sleep and sensory physiology. A review. Journal of Sleep Research, 6, 61-77. https://doi.org/10.1046/j.1365-2869.1997.00031.x

Velluti, R. A. (2018). The auditory system in sleep (2nd ed.). Elsevier-Academic Press, United Kingdom.

Velluti, R. A., Pedemonte, M., Suárez, H., Bentancor, C., \& Rodriguez-Servetti, Z. (2010). Auditory input modulates sleep: An intra-cochlear implanted human model. Journal of Sleep Research, 19(4), 585-590. https://doi.org/ 10.1111/j.1365-2869.2010.00829.x

Vermeire, K., Heyndrickx, K., De Ridder, D., \& Van De Heyning, P. (2007). Phase-shift tinnitus treatment: An open prospective clinical trial. B-ENT, 3(7), 65-69. Davis, P. B.

Vinogradova, O. S. (2001). Hippocampus as comparator: Role of the two input and two output systems of the hippocampus in selection and registration of information. Hippocampus, 11, 578-598. https://doi.org/10.1002/ hipo. 1073

Wallenstein, G. W., Eichenbaum, H., \& Hasselmo, M. E. (1998). The hippocampus as an associator of discontiguous events. Trends in Neuroscience, 21, 317-323. https://doi. org/10.1016/S0166-2236(97)01220-4

Wazen, J. J., Daugherty, J., Pinsky, K., Newman, C. W., Sandridge, S., Batista, R., Ramos, P., \& Luxford, W. (2011). Evaluation of a customized acoustical stimulus system in the treatment of chronic tinnitus. Otology \& Neurotology, 32(4), 710-716. https://doi.org/10.1097/ MAO.0b013e318217d459

Wilde, R. A., Steed, L., \& Hanley, P. J. (2008). Treatment of tinnitus with a customized acoustic neural stimulus: A controlled clinical study. Ear, Nose \& Throat Journal, 87(6), 330-339. 